\title{
Exploring the Perceptions of Egyptian Hotel Management Educators toward Teaching AlCOHOL SERVICE
}

\author{
Mohamed Fawzi Afifi \\ Lecturer, Hotel Studies Department \\ Faculty of Tourism and Hotels, University of Sadat City
}

\author{
Rania Hafez Ghareeb \\ Lecturer, Hotel Studies Department \\ Faculty of Tourism and Hotels, University of Sadat City
}

\begin{abstract}
Most of the food and beverage syllabi taught in institutions offering hospitality education cover alcoholic beverages service. Besides teaching this theoretically, practical training on bar work may be provided to give students the needed practical experience preparing them to real work life. However, "alcohol in the class" has been argued as a controversial topic. Teaching alcohol in a country with a Muslim majority could be a sensitive issue. Whereas Islam prohibits not only alcohol drinking, but handling as well. This presents a contentious issue for those educators responsible for delivering this course. This paper opted to explore how academics perceive teaching alcohol, a topic that was not studied before.

An Arabic questionnaire was distributed to a number of educators in public and private universities and institutions delivering hospitality education. The survey covered some personal and background questions, in addition to the survey drinking history, attitudes toward teaching of alcohol service, self-perception of religiosity. Results indicated a difference between male and female educators' attitudes toward teaching both alcohol service classes and laboratories. However, a correlation between religiosity and attitudes toward teaching is not evident. Furthermore, a significant association between career advice and perceptions of importance of service classes was found. Similarly, the association between career advice and perceptions of importance of service laboratories proved to be statistically significant.
\end{abstract}

Key words: Alcohol service; Hotel Management; Educators; Religion.

\section{Introduction}

This study is the latest of a string focusing on alcohol service in tourism and hotels management faculties in Egypt. Afifi (2014) studied hotel management students' perceptions of studying alcohol service. Later, Afifi (2015)investigated the work intention in alcohol service of such students. However, the attitudes of academics toward alcohol service teaching remain unexamined. The role of academics in setting the class and influencing their students cannot be underestimated.

Virtually all faculties and institutions delivering hotel management education in Egypt teach food and beverage management and operations. This may be delivered under many names, e.g., food and beverage service, beverage management, restaurant 
management. Alcohol service could be taught as a standalone course or be part of another, e.g., restaurant management (Afifi, 2014).

Educators deliver this subject through lecturing in normal classes and possibly by showing how to prepare and serve alcoholic beverages, i.e., through service laboratories. To prepare them for work life, most institutions necessitate students to embark on summer training in hospitality establishments to cover areas of kitchen, food service and front office operations. However, the study of Afifi (2014) indicated that alcohol service proved to be a controversial subject for the majority of Egyptian hotel management student sand gained much opposition in three public universities, especially from Muslims ones. This is influenced by religion and culture, both do not tolerate alcohol. Nevertheless, the stance of the educators on this is not known yet.

\section{Review of literature}

Teaching alcohol service: There are several issues that represent controversies in teaching different disciplines (Afifi, 2014). A list of some controversial issues emerging within some academic disciplines, e.g., psychology, communication was compiled. With in marketing, regulating alcohol advertising appeared (Payne and Gainey, 2003).

Generally, there is scarce research on alcohol in the Arab and Muslim world. This is negligible when compared to that of Europe and the United States (Afifi, 2015; 2014).

Afifi (2014) questions the "legitimacy" of studying alcohol service where it contradicts religious teachings, namely those of Islam. Nevertheless; nothing is known on the perception of educators toward teaching alcohol service. Indeed, culture shapes how people perceive alcohol (Kjærheim et al., 1995; Warren, 2009).

Prior research focused on investigating students' perceptions of studying alcoholic beverages service (Afifi, 2014). In studying perceptions of serving alcohol, exploring educators perception towards alcohols is crucial, since academics not students are the ones who design curriculum and deliver it.

To fill this void, this piece of research endeavors to explore such positions and how this may/not conflict with their religious convictions and the consequent implications. The main argument presented here is that the religious conviction of educators would impregnate their pedagogical decisions on teaching alcohol service. Most important, Wan and Kong (2012) discovered that most undergraduate in their study reported that faculty educators had "the most positive influence" on their career decision-making.

Religion and alcohol: Christianity and Islam. Christianity. Readers of the bible would come across wine in several places (refer to Proverbs 31: 6-7; Numbers 6:20; Ephesians 5:18 King James Version). Wine is a symbol for Jesus' blood and its use is imperative for the celebration of "Eucharist"(Robinson \& Kenyon, 2009). Christ turned water into wine in a wedding (George, 2003).Generally, if it is reasonably consumed, drinking alcohol is allowed (Robinson \&Kenyon, 2009). However, the New Testament determines that drunkenness is a contravention (Cook, 2006). Noteworthy, there is no uniform point of view among churches toward drinking (Belcher, 2006). The Protestant disdain alcohol and encourage abstention. On the other 
hand, Catholicism (Cunningham, 2009) and Orthodox (Gabra, 2009) are more lenient toward drinking.

Religion and alcohol: Christianity and Islam. Islam Religion. Drinking alcohol is prohibited as it is imposed in the Holy Quran. Many Prophetic traditions have conveyed this prohibition. Muslims must abstain from consuming any substance that can affect their minds and their thought abilities (Al-Qaradawi, 1997). Undeniably, alcohol is a substance that has the capacity to affect one's cognizance (Levine, 1992). Despite this and against the religious rules, some Muslims give themselves the permission to drink alcohol (Bilal et al., 1990). Nurdeng (2009) mentioned that a person could drink alcohol if his life is threatened due to thirst and alcohol is the only available liquid, and then s/he is allowed to drink the amount needed to stay alive. Nevertheless, it can be used for other purposes as in medicine (Ahmed et al., 2006).In addition to the prohibition of alcohol drinking, Prophetic traditions (orders) damned the production, selling, buying and serving and cursed the persons participating in these activities (Al-Qaradawi, 1997). Therefore, working in alcohol service is disapproved in Islam

\section{Methods}

A questionnaire was developed to explore the perceptions of hotel management educators toward teaching alcohol service. It was divided into four main sections. One covered demographics; another segment concerned teaching beverage management. Other parts covered: drinking history, and religiosity.

Religious affiliation was measured by asking respondents: "what is your religion?"three selections were given: Muslim, Christian and other. Perceptions over teaching theoretical and practical study of alcohol service were presented as a hedonic scale of 6 points where: 1 is "totally support" and 6 is "totally opposed."

Drinking was tapped through direct questions: e.g., "Have you ever consumed alcohol?", and answer ranged from "I drink now," "in the past and no longer" and "I have never." Another straightforward question was given to measure religiosity where respondents were asked to rate their degree of religiosity on a scale of 6 points where: 1 is "not religious at all" and 6 is "completely religious." A six-point Likert type scale was used so as not to give the respondents the chance to have undecided standpoints (Richards, 2010).The developed instrument was piloted to ten lecturers. This helped to get feedback on the phrasing and design, and issues emerged were remedied.

The sample included public universities (5), high public institute (1), public institutes (3), private universities (1), and high private institutes (5), offering hospitality education. The entire sample confers a Bachelor of Science (BSc.) degree after four years except the three public institutes, which award a diploma (two years after secondary school study). All of these are affiliated to the Egyptian Ministry of Higher Education.

The questionnaire was administered to academics at hotel studies/hotel management departments. Permission to distribute the questionnaire was secured. On administration, the purpose of the study was explained and verbal directions were communicated. Anonymity and confidentiality were assured. Moreover, a confidentiality statement was put on the cover page. These are important with such 
sensitive study topic. Questionnaires-worded in Arabic-were distributed and collected during regular university hours in the academic year 2013.

\section{Results and Analysis}

Initially, 135 questionnaire forms were distributed. However, only 104 usable questionnaire forms were returned giving a response rate of $77 \%$. Statistical Package for Social Sciences (SPSS) version 16was used to perform the statistical analysis.

Respondents' profile: The mean age of the respondents is 34.99 . The minimum age was 21 and the maximum is 60 years. Males constituted $64.4 \%(n=67)$ of the respondents $(\mathrm{N}=104)$ while females accounted for $35.6 \%(\mathrm{n}=37)$. The overwhelming majority were Muslims; 98 respondents $(\mathrm{N}=104 ; 94.2 \%)$, compared to a meager minority of Christians $(n=6 ; 5.8 \%)$. Bachelor of Science (BSc) was the most obtained educational degree as selected by36 respondents $(\mathrm{N}=104 ; 34.6 \%)$, followed by Doctor of Philosophy (Ph.D.) (32; 30.8\%), Master of Science (MSc) (28; $26.9 \%)$, and diploma $(8 ; 7.7 \%)$. Most respondents worked as a lecturer - holding a Ph.D., ( $\mathrm{N}=104 ; 26 ; 25 \%), 26(25 \%)$ as assistant lecturer, $24(23.1 \%)$ as demonstrator, $19(18.30 \%)$ as tutor, five $(4.80 \%)$ as assistant professor, three $(2.90 \%)$ as practical instructor, and one as a professor $(1 \%) .41(39.42 \%)$ respondents were affiliated to five public universities, $17(16.35 \%)$ worked at one high public institute, one $(0.1 \%)$ worked at one private university, $18(17.31 \%)$ were employed at five high private institutes and $27(26 \%)$ held positions at three public institutes.

Years of teaching experience .The mean of teaching experience years was 9.77, and standard deviation is 7.38. Five respondents (5.40\%) had as few as one-year experience while one (1.10\%) respondent had the longest period, 35 years. The mean of practical experience years was 5.21, standard deviation is 7.55. Remarkably, 27 respondents $(\mathrm{N}=104 ; 29 \%)$ had no practical experience at all.

Scope of experience: Investigating the scope of practical experience responses $(\mathrm{N}=$ 102) showed that "food and beverages" was the most selected area $(55 ; 53.9 \%)$, "front office/housekeeping" came in the second place $(29 ; 28.40 \%)$, followed by "human resources/training" $(12 ; 11.80 \%)$, "marketing/sales" $(5 ; 4.9 \%)$ came before last, while "other" was selected one time (1.0\%). To see how many respondents had an experience of alcoholic beverages service- within those who had some experience in food and beverage $(\mathrm{N}=55), 35(63.6 \%)$ reported having no experience while only $20(36.4 \%)$ answered positively.

Teaching of alcohol service: While 83, out of 104, (79.8\%) mentioned that alcohol service is taught in their educational establishments, only $21(20.20 \%)$ said it was not. The 83 -given the option of multiple choice- who taught alcohol did so as part of another course $(\mathrm{N}=87 ; 58 ; 66.7 \%)$, in 27 cases, it was an independent course $(31 \%)$, while at only two $(2.3 \%)$ it was taught as part of a training program. Only 30 participants $(\mathrm{N}=83 ; 36.1 \%)$ did theoretically teach alcohol service while the majority $(53 ; 63.9 \%)$ did not. It seems that most institutions did not have teaching facilities for alcohol service where 55 respondents $(\mathrm{N}=83 ; 66.3 \%)$ confirmed this with only 28 $(33.7 \%)$ reported their availability. While only 12 participants $(\mathrm{N}=83 ; 14.5 \%)$ confirmed delivering practical teaching of alcohol service, the majority $(71 ; 85.5 \%)$ 
did not. Of the 12 educators who practically taught alcohol service merelytwo (16.7\%) used alcohol while $10(83.3 \%)$ did not.

The importance of teaching alcohol service: Participants $(\mathrm{N}=104)$ were asked if they consider it is important to deliver alcohol service classes and this yielded two groups, the majority $(72 ; 69.2 \%)$ answered positively, i.e., it is important, while $32(30.8 \%)$ answered negatively. Again, respondents $(\mathrm{N}=104)$ were asked about the importance of practically teaching alcohol service, whereas the majority $(57 ; 54.80 \%)$ saw it as important. On the other hand, only 47 (45.20\%) did not hold the same perspective.

Happening of a discussion over alcohol: Seventy six educators $(\mathrm{N}=104 ; 73.1 \%)$ reported the happening of a conversation with their students over alcohol while 28 (26.9\%) did not report this. Those who mentioned the happening of a talk over alcohol where asked about groups (173 responses) which showed interest or provoked this. This revealed that, religious wise, Muslims $(65 ; 37.6 \%)$ were evidently present more than Christians $(15 ; 8.7 \%)$ were. Gender wise, males $(65 ; 37.6 \%)$ outnumbered females $(24 ; 13.9 \%)$. However, "other" -educators did not define exactly which student groups showed interest or provoked this - was selected four times $(2.3 \%)$.

Attitudes toward teaching alcohol service classes: Educators who "completely support" service classes of alcoholic beverages numbered $26(\mathrm{~N}=104 ; 25 \%)$, while 23 $(22.10 \%)$ were "completely opposed" to this. Other educators' positions fall into: "support" (29; 27.90\%), "somewhat support" (4;3.8\%), "somewhat opposed" (11; $10.6 \%)$, "opposed" (11; 10.6\%). Collectively, $45(43.3 \%)$ had some degree of opposition to theoretically teach alcohol compared to $59(56.7 \%)$ who had not. Table (1) shows the distribution of attitudes toward teaching alcohol service classes.

Table 1: Attitudes toward teaching alcohol service classes

\begin{tabular}{cccccccc}
\hline & $\begin{array}{c}\text { Completely } \\
\text { support }\end{array}$ & Support & $\begin{array}{c}\text { Somewhat } \\
\text { support }\end{array}$ & $\begin{array}{c}\text { Somewhat } \\
\text { opposed }\end{array}$ & Opposed & Completely & Total \\
& & & & & & & \\
& & & & & & & \\
\hline $\mathrm{N}$ & 26 & 29 & 4 & 11 & 11 & 23 & 104 \\
$\%$ & 25 & 27.90 & 3.80 & 10.60 & 10.60 & 22.10 & $100.0 \%$ \\
\hline
\end{tabular}

Employing a Mann-Whitney U test (Table 2) revealed a statistically significant difference between Male-having the highest mean rank-and females in their perceptions of alcohol service classes $(U=941.5 ; p=0.035)$. Checking for difference between Muslims - having the highest mean rank - and Christians(Table3) in their perceptions of alcohol service laboratories showed a statistically significant variation $(\mathrm{U}=142.5 ; \mathrm{p}=0.030)$. 
Table 2: Comparison of male and female educators regarding their attitude towardalcohol service classes

\begin{tabular}{lllll}
\hline Gender & $N$ & Mean rank & Sum of ranks & Mann-Whitney U value \\
& & & \\
\hline Male & 67 & 58.61 & 3815.50 & 941.500 \\
Female & 37 & 41.43 & 1644.50 &
\end{tabular}

Asym. Sig. $(2$-tailed $)=0.035, p>0.05$

Table 3: Comparison of Muslim and Christian educators regarding alcohol service classes

\begin{tabular}{lllll}
\hline Religious affiliation & $N$ & Mean rank & Sum of ranks & Mann-Whitney U value
\end{tabular}

\begin{tabular}{lllll}
\hline Muslim & 98 & 54.05 & 5296.50 & 142.500
\end{tabular}

$\begin{array}{llll}\text { Christian } & 6 & 27.25 & 163.50\end{array}$

Asym. Sig. (2-tailed) $=0.030, p>0.05$

Attitudes toward service laboratories: Exploring attitudes towards service laboratories gave a different figure. Educators who completely opposed it numbered $41(\mathrm{~N}=104 ; 39.40 \%)$ while $13(12.5 \%)$ fully supported it. Other educators fall into: "support" (13; 12.5\%), "somewhat support" (4, 3.8\%), "somewhat opposed" (10, $9.6 \%)$, and "opposed" $(23 ; 22.1 \%)$. Largely, $74(71.10 \%)$ had some degree of objection over practically teaching alcohol service compared to $30(28.8 \%)$ who had not. Table 4 displays the distribution of attitudes toward teaching alcohol service laboratories. 
Table 4: Attitudes toward teaching alcohol service laboratories

\begin{tabular}{llllllll}
\hline & $\begin{array}{l}\text { Completely } \\
\text { support }\end{array}$ & Support & $\begin{array}{l}\text { Somewhat } \\
\text { support }\end{array}$ & $\begin{array}{l}\text { Somewhat } \\
\text { opposed }\end{array}$ & Opposed & Completely & Total \\
& & & & & & \\
& & 13 & 4 & 10 & 23 & 41 & 104 \\
$\%$ & 12.50 & 12.50 & 3.80 & 9.60 & 10.60 & 22.10 & $100.0 \%$ \\
\hline $\mathrm{n}$ & & & & & & & \\
\hline
\end{tabular}

A statistically significant difference (Table5) was found between males and females' attitudes toward delivering alcohol service laboratories $(U=830 ; p=0.004)$.

Table 5: Comparison of male and female educators regarding alcohol service laboratories

\begin{tabular}{lllll}
\hline Gender & $N$ & Mean rank & Sum of ranks & Mann-Whitney U value \\
& & & & \\
\hline Male & 67 & 58.61 & 3927.00 & 830.000 \\
Female & 37 & 41.43 & 1533.00 &
\end{tabular}

Asym. Sig. (2-tailed) $=0.004, p>0.05$

However, checking for variation in attitudes toward alcohol service laboratories among Muslims $(n=98)$ and Christians $(n=6)$ proved not to be statistically significant $(\mathrm{U}=181 ; \mathrm{p}=0.101)$.

Reasons for opposing service classes: Exploring the reasons $(\mathrm{N}=94)$ for opposing alcohol service classes given by 39 respondents revealed that most was based on religious grounds $(43 ; 45.7 \%)$, followed by morals $(25 ; 26.6 \%)$, social $(16 ; 17 \%)$, and "do not like this subject" $(10 ; 10.6 \%)$. Examining the reasons $(\mathrm{N}=133)$ for opposing practical teaching of alcohol given by 65 respondents revealed that religion was the major issue $(68 ; 51.1 \%)$, followed by, morals $(34 ; 25.6 \%)$, social $(19 ; 14.3 \%)$, "do not like this subject" $(10 ; 7.5 \%)$ and "other" reasons $(2 ; 1.5 \%)$.

Soliciting advice: Seventy one (68.3\%) respondents said that their students reported facing a problem over alcohol service while $33(31.7 \%)$ did not report that. Issues and problem reported by students to educators varied (130 responses). Having an argument over alcohol service was the most experienced issue $(52 ; 40 \%)$, followed by being forced to serve alcohol $(32 ; 24.6 \%)$, threats to terminate training happened $(26,20 \%)$, mockery $(11 ; 8.5 \%)$ and lastly training was terminated in some cases $(9$; $6.9 \%)$. 
Sixty nine educators $(\mathrm{N}=104 ; 66.3 \%)$ were solicited for advice over alcohol service by students while 35 (33.7\%) were not approached.

Drinking history: Examining the drinking history of the hospitality academics $(\mathrm{N}$ $=104)$ revealed that the majority were life-time abstainers $(86 ; 82.7 \%)$, however, 18 $(17.3 \%)$ have consumed alcohol then abstained. None was drinking at the time of the study. Checking for an association between the drinking history and perceptions of teaching alcohol service classes showed no significant association $\left(\chi^{2}=0.454 ; d f=1\right.$; $p=0.5)$. The same finding applies to the association between the drinking history and perceptions of alcohol laboratories $\left(\chi^{2}=0.560 ; d f=1 ; p=0.454\right)$.

Career advice: Fifty one educators $(\mathrm{N}=104 ; 49 \%)$ did not direct their students to work at alcohol-free operations whereas a very close number did $(53 ; 51 \%)$.A Chisquare test for independence (with Yates Continuity Correction) indicated a significant association between career advice and perceptions of importance of service classes, shown in table6, $\left(\chi^{2}=6.926 ; d f=1 ; p=0.008 ; p h i=-0.279\right)$. Similarly, the association between career advice and perceptions of importance of service laboratories proved to be statistically significant as shown in table7, $\left(\chi^{2}=8.850 ; d f=1 ; p=0.003 ; p h i=-0.311\right)$.

Table 6: Association between career advice and perceptions of importance of service classes

\begin{tabular}{llll}
\hline Career advice & \multicolumn{2}{l}{ Importance } & Total \\
\cline { 2 - 3 } & important & not important & 53 \\
\hline Directed students & 30 & 23 & 51 \\
Did not direct students & 42 & 9 & 104 \\
Total & 72 & 32 & \\
\hline \multicolumn{2}{l}{ Chi-square (with Yates Continuity Correction)6.926, Exact Sig. (2-sided) .008. }
\end{tabular}

Table 7: Association between career advice and perceptions of importance of service laboratories

\begin{tabular}{llll}
\hline Career advice & \multicolumn{2}{l}{ Importance } & Total \\
\cline { 2 - 3 } & important & not important & 53 \\
& 21 & 32 & 51 \\
Directed students & 36 & 15 & 104 \\
Tid not direct students & 57 & 47 & \\
\hline \multicolumn{2}{l}{ Chi-square (with Yates Continuity Correction) 8.850, Exact Sig. (2-sided) .003. }
\end{tabular}


Religiosity: As for the self-perception of religiosity, 49 educators $(\mathrm{N}=101 ; 48.5 \%)$ perceived themselves as "religious," $41(40.6 \%)$ as "somewhat religious," $10(9.9 \%)$ as "totally religious," and one (1\%) as "somewhat unreligious." In the main, apart from one respondent, the remaining 100 reported some degree of religiosity.

A Spearman's Rank Order correlation was run to examine a possible relationship between self-reported religiosity and attitudes toward service classes which showed that no correlation exists between both variables, $(r s(101)=-0.021 ; p=0.839)$. Furthermore, no statistical significant correlation was found between religiosity and educators' attitudes toward alcohol service laboratory, $(r s(101)=-0.007 ; p=0.943)$.

In preparation to check for association between religiosity and directing students to work/not work in alcohol service, religiosity was collapsed to two new categories: "religious" $(\mathrm{n}=100)$ and "not religious" $(\mathrm{n}=1)$. A Chi-square test for independence (with Yates Continuity Correction) yielded no significant association between both variables, $\left(\chi^{2}=0.000 ; d f=1 ; p h i=-.099 ; p=1.00\right)$.

\section{Discussion}

The present study has attempted to investigate the attitudes of hotel management educators toward teaching alcohol service.

The overwhelming majority were Muslims whereas only $5.8 \%$ percent were Christians. Christians represent about 10\% of Egyptians (Central Intelligence Agency, 2013). Nevertheless, it may not seem logic to expect this percentage to be realized in a profession where intellectual merit is the basis, i.e, this is not subject to equal opportunities ora quota system.

The study showed that $29 \%$ of respondents had no practical experience at all which is an alarming figure. As this means that educators do not possess enough industry experience to transfer to students and keep them updated or give them realistic expectations about what is going in real work life.

Regarding the scope of experience, it was observed that food and beverage is a laborintensive area, i.e., it employs a large number of personnel (Chow et al., 2006), and here it came number one area of practical experience. However, the majority had nothing to do with handling alcohol. Noteworthy, the study did not ask the educators about their own experience with alcohol handling, for example, if they avoided alcohol-serving operations.

Though most respondents had alcohol service taught in their places, the majority was not involved in this, neither classes nor laboratories. The majority reported that teaching facilities were not available. Afifi (2014) suggested that lack of such facilities might be attributed toadesire to avoid possible debate over alcohol service. Whereas in the case herein; only two respondents reported using alcohol in teaching. However, this could be a sign of fiscal limitations. Lack of resources was mentioned by Alexander et al. (2009) and Colemanet al. (2002) as ahurdle facing training facilities in hospitality education.

The main finding of this study is that educators seem receptive to teaching this controversial subject. There is no direct prohibition of teaching alcohol service in Islam, unlike selling alcohol. Nevertheless, alcohol service study is contentious and its "legitimacy", from an Islamic angle, is doubted (Afifi, 2014). 
Religious affiliation seems to relate to educators' attitudes toward delivering service classes. However, unexpectedly, it is not linked to attitudes toward giving service laboratories. These results contradict the hotel management students' attitudes toward studying both alcohol service classes and laboratories as found by Afifi (2014). Whereas Christians and Muslims did not differ in their perceptions of service classes but did vary in their perceptions of service laboratories.

It was observed here the congruenceamongstudents in their view of studying alcohol service, as they are more benevolentto service classes than service laboratories (Afifi, 2014), and eduactors. However, a problem might arise when disagreement exist. Hospitality institutions may be prepared and want to review and create guidelines to face such potential situations. Probably the incident that took place in Denmark may alert institutions to this. Whereas a student refused to taste wine or pork. Later, one student suited the school and was compensated $(\mathrm{Cw}, 2012)$.

Gender was related to attitudes toward both theoretical and practical teaching. This interesting finding may merit further investigation. The suggested investigation may adopt a qualitative approach to study this further to gain deeper insights on this.

The controversy of alcohol service is a matter that occupies the minds of students since educators reported the happening of a discussion over alcohol. Educators were sought for counseling over the issue of alcohol handling by their students. In another study, educators were the third source of counseling over alcohol-related issues after family and friends (Afifi, 2014). This hints to the role that educators can play in guiding students.

Regarding Drinking history,it is not surprising to find that life-time abstainers dominated the sample. Drinking statistics provided by the World Health organization for Egyptians showed very low rates (WHO, 2011). However, the "oncedrinkers,"i.e., those who used to drink and ceased constituted $17.3 \%$. This is a high percentage when compared to that of students; 8.3\% ( $\mathrm{N}=218$ ) (Afifi, 2014). Whereas, Kjærheim et al.(1995) suggest that young people are more inclined to heavy drinking than older ones. However, the social milieu and background may affect exposure to alcohol and perception of, and type of alcohol consumed (Ashour, 1995).

Association was foundbetween giving career advice to students and educators perceptions of subject importance sustains the view that eduactors has an influence on students' career path choice. This emphasizes the responsibility that educators undertake as to help students to make informed decisions as for their career. As Afifi (2014) recommends, educators need to inform students, in particular those who want to avoid controversial jobs, of potential "halal work"opportunities. For example, nowadays there are avariety of hotel operationsin the Arab World that are "Shariacompliant" (Henderson, 2010).

Concerning Religiosity, religion was the main reason to oppose delivering both alcohol service classes and laboratories. However, religiosity was not associated with delivering neither service classes nor laboratories. Its influence seems moderate if not negligible. However, this resembles the finding that students intention to work in alcohol service is not related to religiosity (Afifi, 2015).This is a puzzling finding that adds to the complexity and vagueness of this variable and its role in this study, and similar ones, e.g., Afifi(2015) and Afifi (2014). Perhaps Ghandour et al. (2009) observation need to be considered at this point where being a member of a religion 
does not necessarily mean that one observes its instructions or lives by it.In other words, being a Mulsim for example, is not a guarantee of adherence to teachings of Islam.

\section{Conclusions}

Alcohol service is not commonlytaught in the investigated institutions. If taught then it is much likely to be theortical rather than practical. The majority of educators recognize the importance of tecahing alcohol service. Nevertheless, it is a controversial subject. While delivering alcohol service classes are mostly accepted, service laboratories are largely rejected.

Attitudes toward service classes did vary by gender, religious affiliation. Attitudes toward service laboratories did vary by gender, but interestingly not by religious affiliation. Moreover, religiosity did not correlate with attitudes toward alcohol service classes nor with those toward service laboratories.

The perceptions of educatorsmay have some implications on their conduct. The association between giving career advice to students and perceptions of subject importance confirms this.

Arguably, some of the attitudes educators, particularly Muslims, expressed here toward delivering alcohol service education might be experienced by other educators in different parts of the world. This relates to Islam's doctrinerather than to locations, e.g., Egypt.

Limitations and avenues for future research: This study presented some insights on the views of hotel management academics regarding teaching alcohol service. A subject that was not researched before, therefore, a little was found in the literature regarding this topic.

The role of religion in the educational process is highlighted and this gives new perspective on the relationship between religion and hospitality education. Moreover, it adds to knowledge on operating teaching restaurants in terms of possible hurdles to training. This is undertaken in a new cultural setting rather than the tradition alfield, e.g., Europe. Arguably, implications are relevant to other Arab/Muslim countries.

Yet, several limitations of this study should be mentioned here. The study included only Egyptian academics, so generalization is hardly claimed. The small sample size is another issue. Furthermore, the use of self-report measures of drinking and religiosityraises concerns regarding credibility as respondents may give socially desirable answers (Ellison et al., 2008). Moreover, examining religiosity through a solitary question may not exclusively express the concept (Afifi, 2014).

Future researche.g Masters and Doctorate dissertationsand academic papers may seek to focus on a larger sample. Another route may seek to check the quantity and nature of the researchrelated to alcohol service in Egypt.

\section{Acknowledgments}

The researchers would like to thank the academic staff who participated in the study. 


\section{References}

- Ahmed, Q. A., Memish, Z.A., Allegranzi, B. \& Pittet, D. (2006)'Muslim health-care workers and alcohol-based handrubs', The Lancet, 367 (9515), 1025-1027

- Afifi, M. F. (2014) 'How do Egyptian hotel management students feel about studying alcohol service?', Journal of Hospitality, Leisure, Sport \& Tourism Education,14, 15-25

- Afifi, M. F. (2015)'Who will carry the bottle? Investigating hotel management undergraduates' work intention in alcohol service', Journal of Hospitality, Leisure, Sport \& Tourism Education, 16, 1-14.

- Alexander, M., Lynch, P., \& Murray, R. (2009)'Reassessing the core of hospitality management education: The continuing importance of training restaurants', Journal of Hospitality, Leisure, Sport \& Tourism Education, 8, 55-69.

- Al-Qaradawi, Y. (1997)The Lawful and The Prohibited in Islam. Cairo: Al-Falah Foundation

- Ashour, A. (1995)'Egypt'. In: D. B. Health (ed.), International handbook on alcohol and culture. Westport, CT: Greenwood Press. pp. 63-74.

- Belcher, J. R. (2006). Protestantism and alcoholism: Spiritual and religious considerations. Alcoholism Treatment Quarterly, 24, 21-32.

- Bilal,A.M., Makhawi,B., AlFayez, G.,\& Shaltout, A.F.(1990) 'Attitudes of a sector of the Arab Muslim population in Kuwait towards alcohol and drug misuse: An objective appraisal', Drug and Alcohol Dependence, 26, 55-62.

- Central Intelligence Agency. (2013). Egypt. In The world fact book. Available from: https://www.cia.gov/library/publications/the-world-factbook/geos/eg.html (Accessed 20 August 2013)

- Chow, I. H. S., Lo, T. W. C., Sha, Z., \& Hong, J. (2006)'The impact of developmental experience, empowerment, and organizational support on catering service staff performance', International Journal of Hospitality Management, 25(3), 478-495.

- Coleman, P., Jackson, R., Ritchie, C., Roberts, A., \&Snelgrove, M. (2002)An Evaluation of The Content, Appropriateness and Academic Rigour of Food and Beverage Modules Within Undergraduate Hospitality Management Programmes. Oxford: LTSN, Hospitality, Leisure, Sport \& Tourism

- Cook, C.C.H. (2009) Alcohol, Addiction and Christian Ethics. Cambridge: Cambridge University Press

- Cunningham, L. S. (2009). An introduction to Catholicism. Cambridge: Cambridge University Press.

- Cw. (2012). School fined for giving Muslim student choice she had to refuse. The Copenhagen Post. Available from: http://cphpost.dk/news/ school-fined-for-giving-muslim-student-choiceshe-had-to-refuse.1074.html (Accessed 20 February 2013).

- Ellison, C.G., Bradshaw, M., Rote, S., Storch, J. \& Trevino, M. (2008)'Religion and alcohol use among college students: Exploring the role of domain specific religious salience', Journal of Drug, Issues, 38,821-846

- Gabra, G. (2009) The A to Z of the Coptic Church. Lanham, MD: Scarecrow Press

- George, R. (2003) 'Drinking Wine'. In: M. Sanler\& R. Pinder (eds.) Wine: A specific exploration. London: Talyor and Francis pp. 1-20

- Ghandour, L.A., Karam, E.G., \& Maalouf, W.E.(2009)'Lifetime alcohol use, abuse and dependence among university students in Lebanon: Exploring the role of religiosity in different religious faiths', Addiction, 104, 940-948.

- Henderson, J. C. (2010). Sharia-compliant hotels. Tourism and Hospitality Research, 246-254.

- Kjærheim, K., Mykletun, R., Aasland, O. G., Haldorsen, T., \& Andersen, A. (1995)'Heavy drinking in the restaurant business: The role of social modeling and structural factors of the workplace', Addiction, 90, 1487-1495.

- Levine, H. G. (1992)'Temperance cultures: Concern about alcohol problems in Nordic and English- speaking cultures'. In: M. Lader, G. Edwards\& D.C. Drummond (eds.) The Nature of Alcohol and Drug-Related Problems. New York: Oxford University Press pp. 15-36. 
- Nurdeng, D. (2009)' Lawful and unlawful foods in Islamic law focus on Islamic medical and ethical aspects', International Food Research Journal, 16, 225-234.

- Payne, B. K. and Gainey, R. R. (2003). 'Understanding and developing controversial issues in college courses', College Teaching, 51 (2), 52-58

- Richards, G. (2010)'The traditional quantitative approach. Surveying cultural tourists: Lessons from the ATLAS cultural tourism research project'. In: G. Richards and W. Munsters (eds.)Cultural tourism research methods. Oxford: CABI. 13-32.

- Robinson, S. J., \& Kenyon, A.J. (2009) Ethics in the Alcohol Industry. Hampshire: Palgrave Macmillan

- Wan, Y.K.P., Kong, W. H. F. (2012)'Career perceptions of heritage management Studies: A case study of undergraduates in Macao', Journal of Hospitality \& Tourism Education, 24(1), 5-15.

- Warren, R.C. (2009)'Temperance and alcohol', Worldwide Hospitality and Tourism Themes, 1, 97-109

- World Health Organization (WHO)(2011)Global status report on alcohol and health. Available from: http://www.who.int/substance_abuse/publications/ global_alcohol_report/en/index.html (Accessed 25 March 2013). 
